\title{
THE DEVELOPMENT OF LABORATORY EQUIPMENT FOR TESTING THE CHARACTERISTICS OF UNSATURATED SOILS
}

\author{
Marius Lucian BOTOȘ ${ }^{1}$, Ferdinánd-Zsongor GOBESZ ${ }^{2}$, Zsombor KISFALUDI-BAK ${ }^{3}$ \\ Technical University of Cluj-Napoca, Faculty of Civil Engineering, Department of \\ Structural Mechanics, Cluj-Napoca, Romania \\ ${ }^{1}$ marius.botos@mecon.utcluj.ro \\ 2go@mecon.utcluj.ro \\ 3 zsombi_kisfaludi@yahoo.com
}

\begin{abstract}
The laboratory assessment of the hydraulic characteristics of unsaturated soils usually requires expensive equipment and an extended time period. With lack of financial support, yet taking advantage of local knowledge and resources, the development of cheaper alternative equipment is presented in the present paper. The automated setup allows the assessment of the saturation degree of soil samples subjected to different suctions.
\end{abstract}

Keywords: laboratory, equipment, testing, unsaturated, soil, water.

\section{Introduction}

The behavior of earth structures can be decisively influenced by groundwater. The amount of water entering the soil can be deduced through seepage studies, which can be carried out by drilling tests or by combining practical and theoretical methods. It is particularly important to carry out such tests on earth structures where safety is the goal.

In the case of labile slopes infiltrated or washed by precipitation, or in the case of water reservoirs with fluctuating levels, a significant change in the boundary conditions applied to these calculations may require an investigation of unsaturated soils. In such situations, the assessment of the hydraulic characteristics (degree of saturation, water retention and storage capacity, permeability coefficients for various suctions, etc.) is the initial step.

These characteristics can be defined in several ways, such as direct laboratory methods, stationary [1] or non-stationary conditions [2], or even directly in the field [3]. The problems arise when the calculated values are quite near the saturation curves [4-6], above which the soil is saturated.

Since direct procedures are very time consuming and costly, over time and almost naturally, several indirect methods have been developed to calculate the hydraulic characteristics of soils based on the WRC (water retention curve) and the SWCC (soil-water characteristic curve) [7-10] .

Very specialized equipment and experienced, well trained staff are needed in order to define these curves in laboratory conditions. Electrical or heat sensors connected 
to gypsum elements or to metal rods, together with tension meters can be used to apply the axis translation technique [11], through which different suction levels are generated and maintained until the gaswater balance is achieved. It is also possible to detect moisture at different suction levels using the axis translation technique without electrical or thermal sensors, for example by applying filter paper on the soil samples and comparing it to a dry sample.

\section{Calculation method}

As is known, the unsteady motion in unsaturated media can be determined based on Richard's equation:

$$
\begin{array}{r}
\frac{\partial}{\partial x}\left(k_{x}(h) \frac{\partial h}{\partial x}\right)+\frac{\partial}{\partial y}\left(k_{y}(h) \frac{\partial h}{\partial y}\right)+ \\
+\frac{\partial}{\partial z}\left(k_{z}(h) \frac{\partial h}{\partial z}\right)=C(h) \frac{\partial h}{\partial t}
\end{array}
$$

In the above equation $k_{x}(h), k_{y}(h)$ and $k_{z}(h)$ are the hydraulic conductivity coefficients; $C(h)$ is the capillary capacity (each as a function of the $h$ suction). The degree of saturation can be determined with the following formula:

$$
S_{e}=\frac{\theta-\theta_{r}}{\theta_{s}-\theta_{r}} k
$$

where $\theta_{s}$ denotes the moisture in saturated state (90-92\%) and $\theta_{r}$ is the residual moisture (the humidity remaining in the soil sample at $1500 \mathrm{kPa}$ suction). The $\theta$ moisture content or the $S_{e}$ degree of saturation can be determined through the axis translation technique for different suction levels.

In order to get a derivable expression, the shape of the function illustrated in Figure 1. must be continuous. This can be achieved by selecting and applying proper approximate formulas. From the variants offered by the literature, the following two were chosen:
Brooks and Corey [10]:

$$
S_{e}=(\alpha|h|)^{-\lambda}
$$

and van Genuchten [7]:

$$
\begin{aligned}
& S_{e}=\left[1+(\alpha|h|)^{n}\right]^{-m} \\
& S_{e}=\left[1+(\alpha|h|)^{n}\right]^{-(1-2 / n)} \\
& S_{e}=\left[1+(\alpha|h|)^{n}\right]^{-(1-1 / n)}
\end{aligned}
$$

The problem can be considered partially solved when the value of the $\alpha$, and $\lambda$ parameters, and the $\alpha, \mathrm{m}$ and $\mathrm{n}$ parameters are obtained in such manner, in which the degree of saturation depicting the $\mathrm{Se}(\mathrm{h})$ function most accurately covers the results of the experimental measurements (Figure 2).

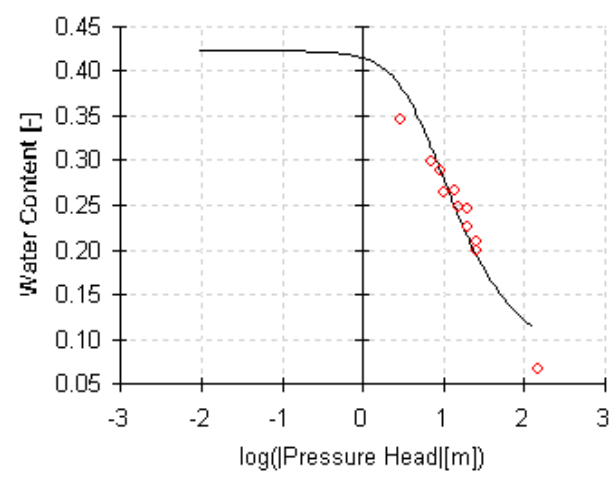

Figure 1.The „, $\Theta$ vs. $\log h$ ” characteristic curve.

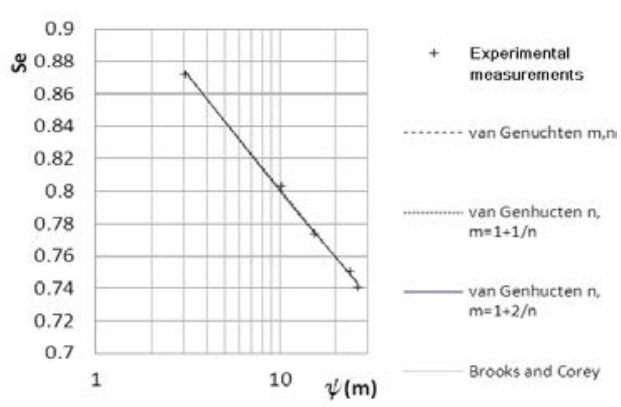

Figure 2. Comparison of calculation results with the values of experimental measurements. 


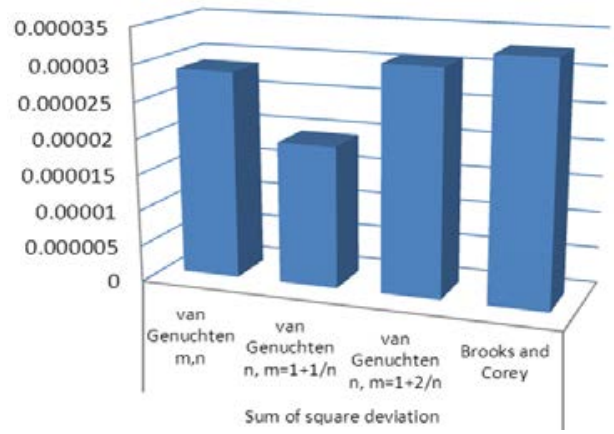

Figure 3. Differences between the applied theoretical calculation procedures.

After successfully selecting the model that best approximates the experimental measurement data, the above mentioned shape parameters can be used to calculate the $k_{r}$ relative hydraulic conductivity.

Brooks and Corey's formula for the Burdine model [12] takes the following form:

$$
k_{r}=S_{e}^{l+1+2 / \lambda}
$$

While in the case of the Mualem model [10] it will be:

$$
k_{r}=S_{e}^{l+2+2 / \lambda}
$$

Van Genuchten's formula in the case of applying the Burdine model [12]:

$$
k_{r}=S_{e}\left[1-\left(1-S_{e}^{1 / n}\right)^{n}\right]
$$

and, written for the Mualem model [10]:

$$
k_{r}=S_{e}\left[1-\left(1-S_{e}^{1 / n}\right)^{n}\right]^{2}
$$

The hydraulic conductivity of the unsaturated soil will be calculated by multiplying the hydraulic conductivity of the saturated soil with the relative hydraulic conductivity obtained through one of equations (4a) to (4d).
Figure 4. shows the variation of the hydraulic conductivity calculated based on the water retention curves with the parameters obtained from Brooks and Corey's formulas, in case of the Burdine and Mualem models.

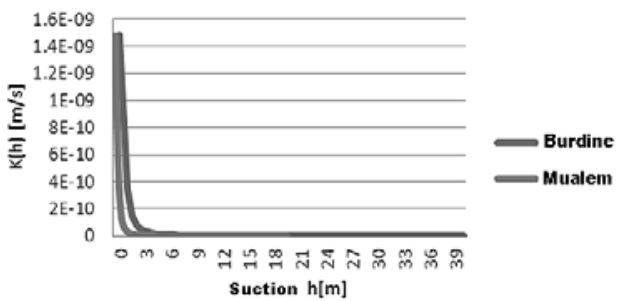

Figure 4. The variation of the hydraulic conductivity depending on suction values (applying the Burdine and the Mulaem models).

\section{Testing equipment}

In order to apply the indirect methods, the soil-water characteristic curves and the hydraulic conductivity for the saturated soil sample should be determined in a laboratory environment, as described in the previous chapter.

For this purpose the constant gradient permeameter is used in case of porous and loose (highly permeable) soils, while in the case of low water-permeable soils, the variable gradient permeameter is used. To assess the hydraulic conductivity for a saturated state, the following expression can be used (based on Darcy's law, which can be written in several ways, depending on which values are measured):

$$
q=v \cdot A=K_{\text {sat }} \cdot i \cdot A
$$

In the above formula, $q$ is the flux (the ceded water volume), $K_{\text {sat }}$ is the hydraulic conductivity in a saturated state, $i$ is the hydraulic gradient and $A$ is the size of the permeable section.

The flux may also be determined by weight or volume (for example, by using a precision balance for the mass or a burette 
for the volume). In the case of the constant gradient permeameter:

$$
q=\frac{V}{\Delta t}=\frac{m \cdot g}{\gamma \cdot \Delta t}
$$

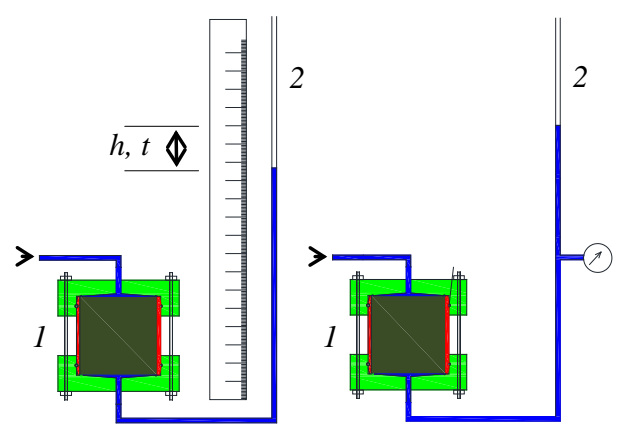

Figure 5. Scheme of manual and automatic data reading permeameter with: 1 - chamber containing the saturated soil sample, 2 - transparent tube.

If the pressure gauge is placed on the same level with the water input (Figure 5.), the hydraulic gradient value, depending on the $p$ pressure displayed on the gauge and on the $L$ length of the soil sample, can be obtained by:

$$
i=\frac{p}{\gamma \cdot L}
$$

In the case of manual reading (Figure 5) the above formula will be as shown below:

$$
i=\frac{h}{L}
$$

When using a variable gradient permeameter, the flow intensity can be calculated from the $\Delta h$ difference measured in the transparent tube (with diameter $d$ ):

$$
q=\frac{\Delta h \cdot \pi \cdot d^{2}}{4 \cdot \Delta t}
$$

When using a pressure gauge, the previous formula can be re-written as follows:

$$
q=\frac{\Delta p \cdot \pi \cdot d^{2}}{\gamma \cdot 4 \cdot \Delta t}
$$

For the axis translation technique, the same equipment can be used as for measuring the permeability in saturated media, but instead of water, air is introduced into the chamber and the bottom filters are replaced with a HAES (High Air Entry Stone) plate (Figure 6.). This plate, through the size and shape of its pores, prevents the passage of air until a certain pressure (defined during production as a characteristic value). However, the water from the soil sample can get out through this plate, as long as it comes directly to it (for this reason the HAES plate should be saturated before placing it in the testing chamber).

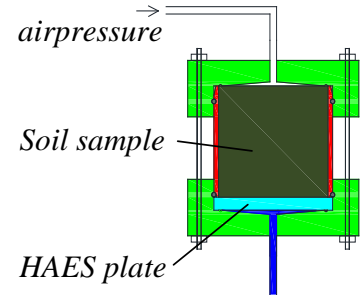

Figure 6. Scheme of a testing chamber for measuring the permeability of unsaturated soils.

Of course, the amount of water seeping through the soil sample can be measured (as already mentioned, either by electronic weighing scale or by a precision burette), thus yielding the flow intensity.

The pressure required to establish the equilibrium state is set and maintained by a regulator, but in the case of low suction values this may prove difficult to achieve. In such cases (under 20-30 kPa suction values) a pressure-free device may be used so as to maintain a constant suction on the bottom of the HAES plate, relative to the atmospheric pressure in the chamber. This constant suction effect is most easily provided with an output overflow (keeping unchanged the discharge level). 
These measuring cycles are a very timeconsuming process and require the presence of a human operator for periodic checks in order to detect the equilibrium state, so their automation can be useful. Automation is really needed when several soil sample tests are to be carried out in parallel, since in such cases the setting of pressure levels and the detection of equilibrium states require very attentive tracing and a lot of time. Figure 7. shows the scheme of the proposed automated equipment, controlled and driven by a device with a microcontroller.

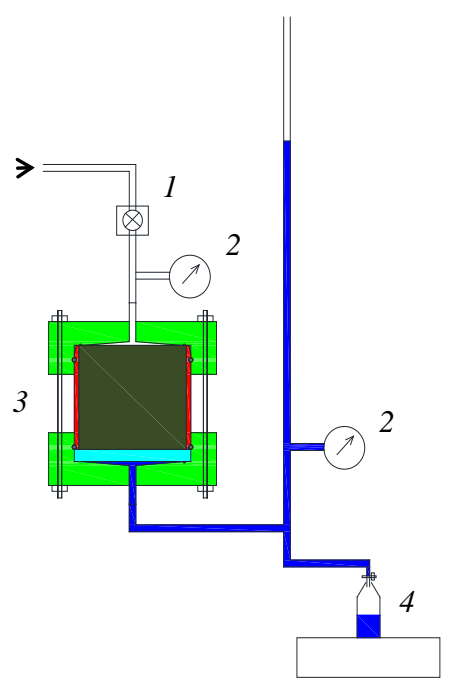

Figure 7. Schematics of automated equipment for measuring unsaturated soil samples (1 - microcontroller controlled air pressure regulator; 2 - pressure sensor connected to microcontroller; 3 chamber containing the unsaturated soil sample, with the HAES plate underneath; 4 - electronic scale connected to the microcontroller).

\section{Implementation and use}

Based on the aforementioned, automated equipment has been developed at our department's hydraulic laboratory to allow the assessment of the hydraulic characteristics of several soil samples in parallel processes without the need for human supervision.

Two types of experimental chambers were made, one larger, steel-plated (Figures 8 and 9), and six smaller with a plastic or Plexiglas covering (Figure 10). The larger sized steel casing can withstand up to 15 bar pressure, while the smaller chambers were tested only up to 3 bars.
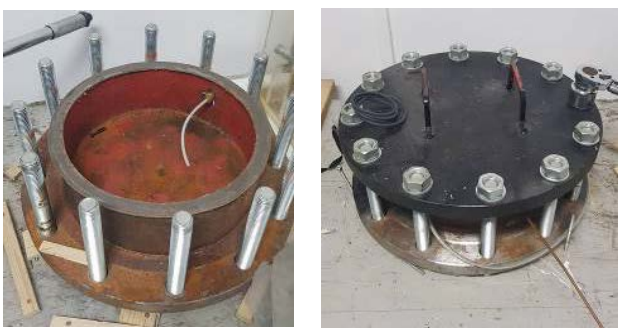

Figure 8. Images of the testing chamber for measuring the permeability of unsaturated soil samples subjected to higher pressure (disassembled on the left, closed on the right).

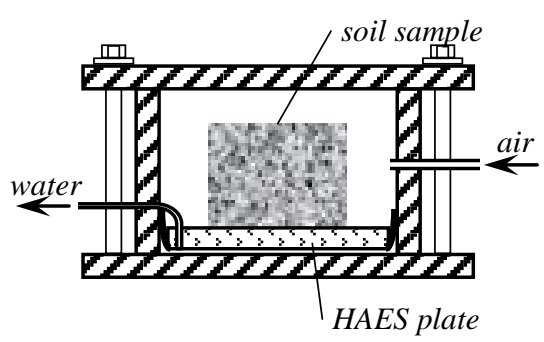

Figure 9. Cross section of the testing chamber for measuring the permeability of unsaturated soil samples subjected to greater pressure.

One of the smaller testing chambers designed for measuring the permeability of unsaturated soil samples subjected to lower pressure (made according to the scheme from Figure 6) is shown in Figure 10. Through the plexiglass base, the HAES plate and the sealing ring are visible, and the precision burette is located next to the chamber. 


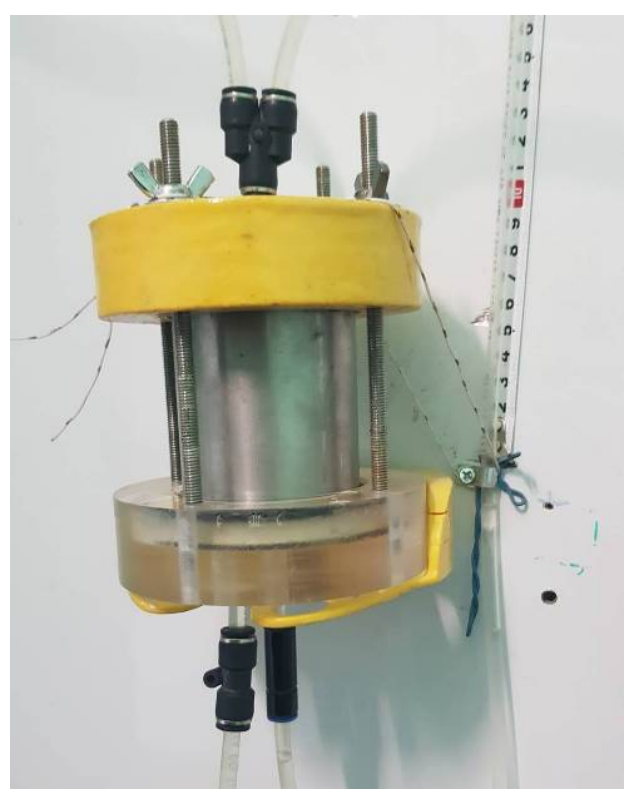

Figure 10. One of the smaller testing chambers.

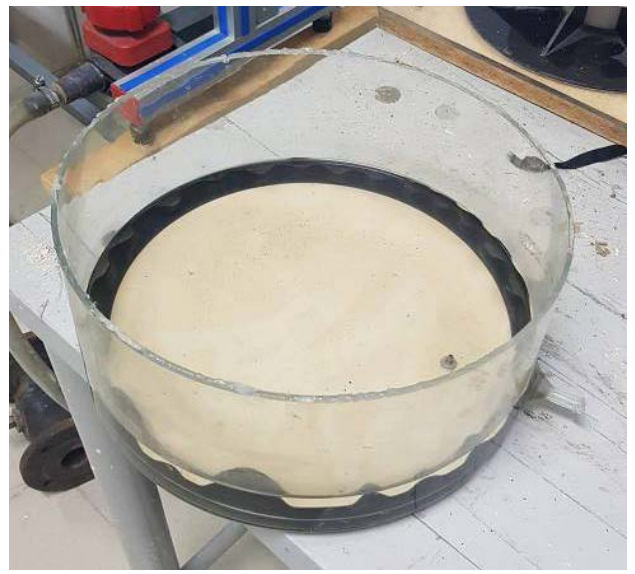

Figure 11. The larger HAES plate during soaking (saturation).

The more expensive components were the HAES plates (Figure 11), as the laboratory was already equipped with a compressor.

The automation was achieved based on a programmable "element14 BeagleBone Black" [13, 14] unit equipped with a $1 \mathrm{GHz}$ ARM Cortex A8 processor, 512 MB memory and 4 GB storage capacity
(Figure 12). Zsolt Simon, computer engineer student, dealt with the programming of the unit most of the time.

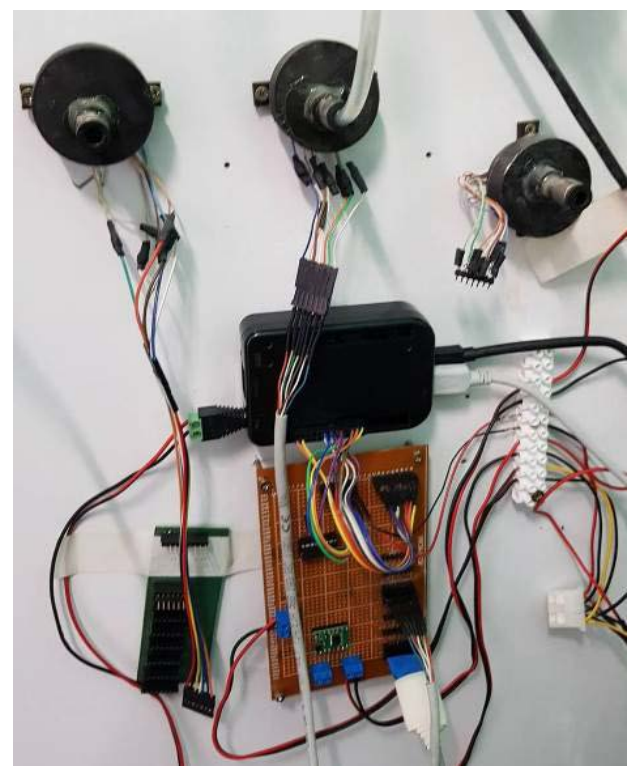

Figure 12. The microcontroller based device (with some connections below, and 3 pressure sensors above).

In the first version, the microcontroller unit was connected to a computer, and the system could perform parallel measurements and computing for up to ten soil samples by performing the following steps:

- Pressure control and adjustment (starting from a pre-set level, then passing through all the stages scheduled before the measurement);

- Acquiring the water level from the burette or from the piezometer (to assess the water volume that leaked from the soil sample, and when to pass to the next pressure level);

-Guiding and controlling the solenoid valves in parallel (to allow accurate weighing of the water separately for each soil sample for each reached and recorded equilibrium level);

- Transfer of data, a data base and drawing the retention curves; 
- Running the algorithm that selects the most suitable equation in order to obtain a continuous function for the degree of saturation and finding the matching parameters;

-Computing of all hydraulic parameters and plotting the variation curves;

- Build and record the variation curves of diffluent volumes over time, for each pressure range, in order to allow the assessment of the diffusivity;

- Announce the completion of the determinations for the tested soil samples (by email message).

This system also allowed remote human intervention (control, monitoring) through a web interface.

As a result of subsequent improvements, the intermediate computer was excluded from the system, the microcontroller unit being connected through a HDMI connection to a display.

In the current configuration, three smaller (low pressure) permeability meters are in parallel function with the higher pressurized steel chamber (due to the limited number of the available HAES plates). The required air pressure for these testing chambers is provided by a compressor and it can be adjusted to varying levels for each testing unit by the microcontroller driven pressure control subunits (Figure 13).

In the near future, the plastic pipe extending from the HAES plate will be replaced with a neoprene tube in the steel coil chamber and the inlet pressure will be through a steel pipe (as we think the current copper tube's plasticity can affect the measurements).

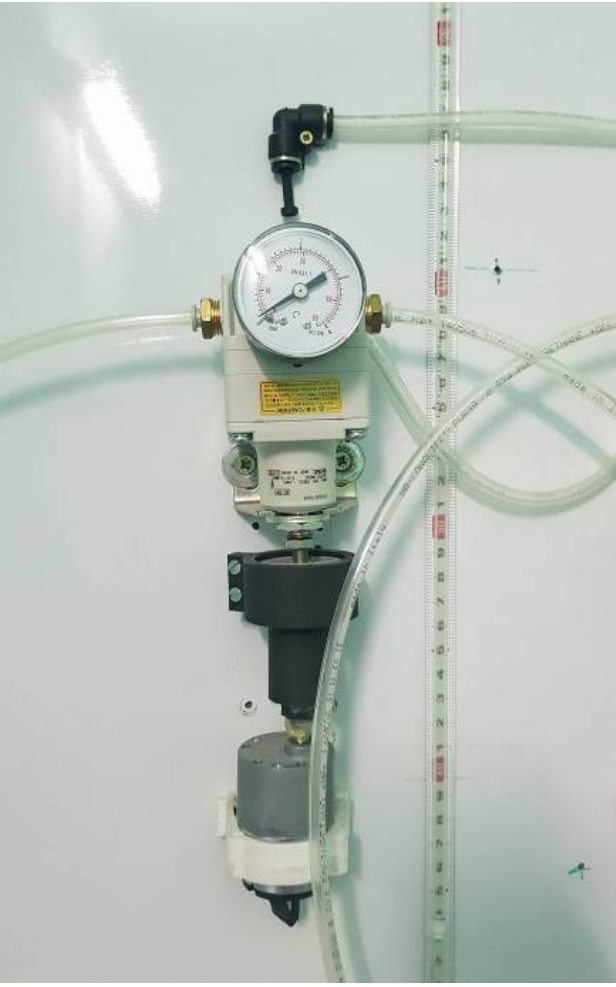

Figure 13. A pressure measurement and control sub-unit (with a burette in the background).

\section{Conclusions}

At a relatively low cost (and by enthusiastic work), experimental equipment was created to make such measurements as are found in well-equipped laboratories. Thus, the range of research possibilities was widened.

So far, the operation of the experimental apparatus has shown that, in addition to student research work, practicing professionals can also efficiently use it to study unsaturated soils.

Due to automation, human presence and intervention are not required during the time consuming tests. The possibility of performing multiple measurements and calculations simultaneously (the number of 
which can be further increased in the future) is also noticeably time saving.

In addition to defining the hydraulic characteristics of the unsaturated soils based on the characteristic curves, the equipment also offers an opportunity to address questions related to the gas permeability, shear resistance or thermal conductivity of different soil samples.

\section{References}

[1] Klute A.: Laboratory measurement of hydraulic conductivity of unsaturated soil. Methods of Soil Analysis, Mono. 9, Part 1. American Society of Agronomy, Madison, WI, USA, 1965, 253-261.

[2] Hamilton J. M., Daniel D. E., Olson R. E.: Measurement of hydraulic conductivity of partially saturated soils. Permeability and Groundwater Contaminant Transport. ASTM Special Technical Publication 746, 1981, 182 $-196$.

[3] Watson K. K.: An instantaneous profile method for determining hydraulic conductivity of unsaturated porous materials. Water Resources Research 2/4. (1966), 709-715. https://doi.org/10.1029/WR002i004p00709

[4] Gardner W. R.: Calculation of capillary conductivity from pressure plate out flow data. Soil Science Society of America 20/3. (1956) 317-320.

https://doi.org/10.2136/sssaj1956.036159950 02000030006x

[5] Benson C. H., Gribb M. M.: Measuring unsaturated hydraulic conductivity in the laboratory and field. In: Unsaturated Soil Engineering Practice (eds: Houston, S. L., Fredlund, D. G.) American Society of Civil Engineers GSP 68, New York, NY, 1997, 113168.

[6] Leij F. J., van Genuchten M. Th.: Characterization and measurement of the hydraulic properties of unsaturated porous media. (eds.: van Genuchten M. Th., Leij F. J., Wu L.), Proceedings of International Workshop on Characterization and Measurements of the Hydraulic Properties of Unsaturated Porous Media. U.S. Salinity Laboratory and Univer- sity of California, Riverside, CA, October 2224, 1997, 31-42.

[7] Brooks R. H., Corey A. T.: Hydraulic properties of porous medium. Hydrology Paper 3. Colorado State University, Fort Collins, Colorado, USA, 1964.

https://mountainscholar.org/bitstream/handle/ 10217/61288/HydrologyPapers_n3.pdf?seque nce

[8] Fredlund D. G., Xing A., Huang, S.: Predicting the permeability function for unsaturated soil using the soil-water characteristic curve. Canadian Geotechnical Journal 31/4. (1994), 533-546.

https://doi.org/10.1139/t94-062

[9] Mualem Y.: A new model for predicting the hydraulic conductivity of unsaturated porous media. Water Resources Research 12/3. (1976) 513-522.

https://doi.org/10.1029/WR012i003p00513

[10] Van Genuchten M. T.: A closed-form equation for predicting the hydraulic conductivity of unsaturated soils. Soil Science Society of America Journal 44/5. (1980) 892-898.

http://doi.org/10.2136/sssaj1980.0361599500 4400050002x

[11] Vanapalli S. K., Nicotera M. V., Sharma R.S.: Axis translation and negative water column techniques for suction control. In: Laboratory and Field Testing of Unsaturated Soils (eds.: Tarantino A., Romero E., Cui Y. J.) Springer, Dordrecht, 2009, 33-48. https://doi.org/10.1007/978-1-4020-8819-3_4

[12] Burdine N. T.: Relative Permeability Calculations From Pore Size Distribution Data, Transactions of the American Institute of Mining \& Metallurgical Engineers, 198, (1953) $71-78$. https://doi.org/10.2118/225-G

[13] Coley G.: element14 BeagleBone Black System Reference Manual, Premier Farnell, 2014, https://cdn.sparkfun.com/datasheets/ Dev/Beagle/e14 BBB_SRM_rev 0.9.pdf (accessed: October 2017).

[14] BeagleBoard.org, BeagleBone. https://beagleboard.org/bone (accessed: October 2017). 